\title{
ALEXANDER DIE GROTE SE LEËR EN DIE OORLOGSTRES-SINDROOM, 326 v.C.
}

\author{
L Cilliers \& F P Retief (Universiteit van die Vrystaat)
}

In die somer van 326 v.C. is Alexander die Grote se Asiatiese veroweringsveldtog van sewe jaar onverwags aan die bolope van die Indus-rivier gestuit - nie deur vyandelike aksie nie, maar deur die weiering van sy soldate om verder ooswaarts te trek. 'n Moontlike rede vir sulke drastiese optrede deur 'n leër wat hul koning tot op daardie stadium blindelings gevolg het, is dat erge oorlogstres kon ingetree het. Die oorlogstres-sindroom, soos vandag gedefineer, is goed nagevors, en in hierdie artikel word die moontlikheid ondersoek dat dit by bovermelde geleentheid 'n beslissende rol kon gespeel het. Sou dít dalk die verklaring kon wees vir hierdie dramatiese gebeurtenis waarin Alexander se droom van 'n ryk wat tot aan die einde van die wêreld strek, verpletter is - deur sy eie soldate?

\section{Oorlogstres}

\section{Voorkoms}

Die eerste beskrywing van oorlogstres as oorsaak van spesifieke psigiese disintegrasie by soldate, dateer terug na die Amerikaanse Burgeroorlog (1861-1865). Hammond, Geneesheer-generaal van die Noordelike magte, het dit destyds "nostalgie" genoem, 'n vorm van erge bedruktheid veroorsaak deur verlengde verwydering van huis en familie (Louw 1989:145-148; Bourne 1969:219-236). Tydens die Eerste Wêreldoorlog is 'n vergelykbare toestand herken en "bomskok" genoem. Dit is toegeskryf aan mikro-vaskulêre breinskade veroorsaak deur nabye bomontploffings, maar mettertyd is besef dat slegs 'n klein minderheid van hierdie pasiënte inderdaad organiese breinletsels opgedoen het. So het psigiese trauma as etiologie sterk na vore getree (Louw 1989; Marmar \& Horowitz 1988; Bourne 1969).

Gedurende die Tweede Wêreldoorlog is die omvang en aard van gevegstres duideliker omlyn en is verwys na "operasionele uitputting" ("combat exhaustion/ fatigue") - selfs "oorlogsneurose". In die Koreaanse Oorlog is na "gevegsuitputting" ("combat fatigue") verwys, en tydens die Viëtnam-oorlog het die benaming "posttraumatiese stresafwyking" ("post-traumatic stress disorder" of PTSD) populêr geraak (Louw 1989; Marmar \& Horowitz 1988; Bourne 1969). Meer plaaslik het Feinstein en Potgieter hierdie sindroom in die Angolese grensoorlog nagevors, en hul resultate stem grotendeels ooreen met veral die Viëtnam-ervaring (Louw 1989).

Die voorkomssyfer van gediagnoseerde oorlogstres in die verskillende oorlogsituasies is deur Bourne (1969:219-236) en Allerton (1969:10-140) saamgevat. Tydens die Amerikaanse Burgeroorlog is "nostalgie" by 2,3-3,3 per 1000 soldate gevind. 'n Verdere 20,8 per 1000 is met verlamming, en 6 per 1000 met 'n diagnose van kranksinnigheid ontslaan. Tydens die Eerste Wêreldoorlog was die insidensie van "bomskok" onder die Geallieerdes ongeveer een-derde van vergelykbare oorlogs- 
uitputting in die Tweede Wêreldoorlog, wat op 10\% van die soldate geskat is. Hierdie syfer is heeltemal spekulatief: in die Europese kampanje het die VSA 'n voorkoms van 101 per 1000 soldate aangemeld. Interessant genoeg het die Duitse Weermag in geen van die twee oorloë so 'n sindroom aangeteken nie (Glass 1969). Tydens die Koreaanse oorlog is gevegsuitputting by 37 per 1000 soldate gediagnoseer, en in Viëtnam het PTSD by 10-12 per 1000 vegtendes voorgekom (alhoewel die kontrolering van pasiënte oor 'n langer tydperk 'n ver hoër voorkoms van minstens $20 \%$ getoon het). In die Angolese grensoorlog was die langtermynvoorkoms 26\% (Louw 1989).

\section{Kliniese beeld}

Die simptoom-kompleks is uiters variërend en benewens die akute sindroom, mag dit selfs jare later as 'n vertraagde siektetoestand voordoen. Die Amerikaanse Psigiatriese Vereniging het baanbrekerswerk gedoen deur gestandardiseerde diagnostiese kriteria op te stel wat aanvanklik in 1952 in hul Diagnostic Statistics Manual (DSM) verskyn het. Dit is mettertyd aangepas en die sg. DSM-III-kriteria word steeds as normatief aanvaar (Louw 1989; Marmar \& Horowitz 1988; Elder \& Clipp 1988).

Die simptoomkompleks wat in Viëtnam tipies vroeg ontstaan het (50\% van gevalle in die eerste drie maande na aankoms op die gevegsterrein), word deur die volgende faktore beïnvloed: die graad van gevegstrauma, persoonliksheidstipe (hoër voorkoms by emosioneel onstabiele persone), gesondheidstatus, individuele aanvaarding van die oorlogsmilieu (bv. regverdigheid van die oorlog) en vertroue in gevegsleiers (Tischler 1969:19-45). Dit word ook aanvaar dat afhangend van die omvang van stres, alle persone waarskynlik wel 'n "psigiese breekpunt" sal hê, en dat mindere/enkele simptome selfs by andersyds "normale" soldate voorkom (Marmar \& Horowitz 1988).

Volgens die DSM-III-vereistes word die sindroom gesien as 'n verbygaande sielkundige afwyking by 'n basies gesonde persoon, en berus die diagnose op die volgende kriteria (Elder \& Clipp 1988):

(i) Blootstelling aan aansienlike oorlogstres;

(ii) Herlewing van trauma-momente deur nagmerries, onwillekeurige terugflitse en ontstellende herinneringe;

(iii) Emosionele afstomping en sosiale onttrekking;

(iv) Persoonlikheidsafwykings soos patologiese skuldgevoelens, hiperaktiwiteit, selektiewe geheueverlies en slaapafwykings. Alles dui op psigiese disintegrasie, dikwels geassosieer met aggressiwiteit en wantroue, anoreksie, alkohol- en dwelmverslawing, depressie, erge moegheid en gebrek aan inisiatief. 


\section{Behandeling en prognose}

Ondervinding, veral tydens die Viëtnam oorlog, het in die meeste gevalle op gunstige resultate gedui. Voorkomende optrede is gebaseer op antisipering van die toestand by kwesbare persone, alhoewel dit onprakties geblyk het om intensiewe sielkundige siftings-programme in te stel. Doeltreffende opvolging was baie belangrik. Behandeling geskied verkieslik naby die gevegsgebied, nie by die basis-hospitale nie, en berus op sielkundige ondersteuning en die skep van 'n positiewe verwagting dat die persoon gou gesond en aktief sal wees. Gepaste geneesmiddelterapie kan nuttig wees. Genesing neem waarskynlik enkele maande, maar by andersins normale persone is die prognose goed (Marmar \& Horowitz 1988; Allerton 1969).

\section{Alexander en sy leër}

Ten einde 'n oordeel te kan vel oor die rol van oorlogstres by die vermelde insident van 326 v.C., is 'n oorsig van die aanleidende gebeure noodsaaklik.

In 334 v.C. het Alexander (22 jaar oud) as koning van Masedonië, Asië binnegeval ten einde die Persiese Ryk op eie bodem aan te durf. Alexander se segetog is welbekend (Hammond 1981). By die veldslae van Granicus (334 v.C.), Issus (333 v.C.) en Gaugamela (331 v.C.) is die Perse beslissend verslaan. Hul koning, Darius III, vlug en word die volgende jaar deur sy eie soldate vermoor. Die Persiese Ryk het tot teenaan die Indus-rivier gestrek, en Alexander het sy veroweringsveldtogte verder oos voortgesit. Teen 327 v.C. is Baktrië en Sogdiana verower wat Alexander by die oosgrens van die voormalige Persiese invloedsfeer bring. Hy steek die Khyber-pas oor na die Indus-vallei waar hy vroeg in 326 v.C. 'n bloedige slag by die Hydaspes/Djelum-rivier (bo-loop van die Indus) wen, en hom dan voorberei om Indië binne te val. Op hierdie stadium vind die beslissende konfrontasie met sy leër plaas (wat hieronder in detail bespreek sal word).

Die samestelling van Alexander se leërmag het in die loop van sy Asiatiese veldtog aansienlik verander. Hy het in 334 v.C. die Dardanelle oorgesteek met ongeveer 35000 man: 30000 infanterie waarvan 12000 Masedoniërs en die res Grieke en ander bondgenote was, en 5000 ruiters, waarvan 1800 Masedoniërs (die sg. Metgeselle of "Companions"), 1800 Thessaliërs, en die res ander bondgenote was. Die Masedoniese komponent wat deurgaans die kern van sy leër sou vorm en oorwegend die offisierskorps sou uitmaak, was dan getallegewys ongeveer $40 \%$ van die totaal (Tarn 1948:1.10-13). Mannekragverliese is deurlopend aangevul deur versterkings uit Masedonië (Hammond 1981:218; Tarn 1948:2.135), huursoldate en konskripsie onder verowerde volke. Alexander se suksesvolle kampanje het daartoe gelei dat huursoldate en vreemde leëreenhede al hoe geredeliker by hom aangesluit het, onder andere vir die rykdom wat uit oorlogsbuit verkry kon word (Hammond 1981:218).

Voor Gaugamela (331 v.C.) het hy aansienlike versterkings (onder andere uit Masedonië) ontvang, en het sy totale leërmag digby 50000 getel, waarvan ongeveer 30\% Masedoniërs was (Tarn 1948:2.182-189). In Baktrië (327 v.C.) het groot getalle soldate (onder andere 'n Masedoniese infanterie-bataljon) weer by hom aangesluit, 
maar was dit nodig om 'n aansienlike komponent hiervan as besettingsmagte in verowerde gebiede agter te laat (Tarn 1948:2.168). Alhoewel hy dus veel meer soldate tot sy beskikking gehad het, was sy leër vir die inval in Indië ongeveer 30000 man sterk (6 500 ruiters en 23500 infanterie). Hiervan was maar ongeveer een-sesde Masedoniërs. Dit het dus vir Alexander al hoe moeiliker geword om eerste-linie infanterie en Masedoniese offisiere in die veld te stoot (Hammond 1981:213-215). Na sewe jaar van oorlogvoering in Asië het Alexander die probleem van 'n drasties uitgedunde Europese leërkern in die gesig gestaar. Hy sou geen verdere versterking uit Masedonië kry nie (Tarn 1948:2.143) en volgens Curtius (9.3.10-11) het sy Masedoniërs al hoe meer bewus geword van die groeiende vreemde kultuur in die leër.

Insident by die Hyphasis/Beas-rivier, 326 v.C.

Dit is belangrik om te verstaan dat Alexander sy Indiese veldtog beplan het met die foutiewe aanname dat Indië relatief klein is, en dat dit binne militêre trefafstand na die ooste as landmassa in die mitiese "Oseaan" (of "Oos-oseaan") eindig. Volgens sy inligting sou hierdie oseaan Asië na die noord-ooste omsirkel, en na die weste aansluit by bekende oseane, die Rooisee, ens. Daar is selfs vermoed dat die Indus op die een of ander wyse by die Nyl kon aansluit. Alexander het 'n groot begeerte gehad om "die einde van die wêreld" by die kus van die "Oos-oseaan" te bereik - en was totaal onbewus van die bestaan van China, Oos- en Suid-oos Asië (Hammond 1981:202-203; Tarn 1948:2.275-285).

Die Indiese veldtog het in die Indus-vallei met die slag van Hydaspes/Djelum teen Porus begin - 'n geveg wat deur Alexander gewen is, maar met aansienlike verliese (Hammond 1981:207-210). Alhoewel 15 olifante reeds by Gaugamela teenwoordig was, het Alexander se leër hier vir die eerste keer met 'n groot aantal (200) oorlogsolifante te doen gekry. Dit het 'n beduidende demoraliserende invloed op sy soldate en offisiere gehad (Curtius 9.2.3). Van die Hydaspes/Djelum het Alexander ooswaarts getrek en ander sytakke van die Indus onder moeilike omstandighede oorgesteek totdat die Hyphasis/Beas-rivier (binne die huidige Punjab) bereik is. Dit was die baie warm monsoen somerseisoen van 326 v.C., en die Arattavolk het hul gebied verbete verdedig. By die inname van Sangala byvoorbeeld het Alexander ernstige verliese gely (Wood 1997:190-197). Volgens Curtius is van Porus (wat ná Hydaspes Alexander se bondgenoot geword het) en ander bronne verneem dat die grootste rivier in Indië (dalk die wêreld), die Ganges, twaalf dae te voet verder oos geleë was, en dat daar in hierdie gebied 'n baie magtige koninkryk was, met 'n leër van meer as 200000 man, 2000 strydwaens en 3000 oorlogsolifante. Porus het egter ook vermeld dat die koning, Aggrammes, 'n swakkeling was, en dat Alexander hom sou kon verslaan (Curtius 9.2.3). Sekere moderne geskiedkundiges twyfel egter of Alexander ooit van die Ganges gehoor het (Tarn 1948:2.280).

Arrianus (Anab. 5.25-29) skryf dat dit onder hierdie omstandighede was dat die Masedoniërs moedeloos geword en in opstand gekom het. Dit was vir hulle duidelik dat ten spyte van ontstellende gerugte oor wat anderkant die Hyphasis voorlê, die koning van plan was om steeds verder te trek. Hulle was bereid om 
Alexander te help om die Persiese Ryk (hul tradisionele vyande) te verower, maar nou wou hy klaarblyklik onbekende wêrelde en gevare in Indië aandurf, en daarvoor het hulle nie kans gesien nie (Tarn 1948:1.97-98). Toe Alexander hoor dat daar ontevredenheid onder sy troepe was, het hy die senior offisiere byeengeroep om, volgens Arrianus (5.25-29), hul van sy beoogde optrede te oortuig - of om deur hulle van 'n ander sienswyse oortuig te word. Dis interessant dat hy alle offisiere byeengeroep het, terwyl slegs die Masedoniërs ontevrede was (Hammond 1981:213215). Daar is inderdaad rede om te glo dat Porus en die nie-Masedonies-Griekse troepe inderdaad bereid (en selfs entoesiasties) was om onder Alexander Indië binne te val (Hammond 1981:213-215). Arrianus (5.25-29) skryf dat Alexander in sy toespraak sy soldate herinner het aan wat hulle reeds bereik en verower het. Daar het slegs 'n beperkte gebied oorgebly, verby die Ganges tot by die Oos-oseaan. Na verowering hiervan, het hy hulle verseker, sou die stryd verby en hulle almal ryk wees van die buit. In sy weergawe van hierdie toespraak lê Curtius (9.2.12-30) klem op Alexander se aanprysing van sy Masedoniese kerntroepe en die afkraking van die bangmaakstories oor wat in Indië sou voorlê.

$\mathrm{Na}$ sy toespraak het 'n lang stilte gevolg, terwyl Alexander gewag het op 'n reaksie van sy leër. Toe het een van sy senior Masedoniese aanvoerders, Coenus (wat enkele weke hierna aan siekte sou sterf, volgens Hammond 1981:213-215), geantwoord, en volgens Arrianus (5.27.2-9) vir Alexander geloof vir sy wyse leiding oor vele jare en die feit dat hy nooit as tiran geheers het nie, maar nou voel die troepe dat daar 'n einde moet kom aan alle stryd. Van die eertydse groot leërmag Masedoniërs is net 'n klein groepie oor, en hulle is nou moeg in gees - selfs meer as in liggaam. Alexander moet nie nou die aanvoerder van onwillige troepe word nie. Oorweeg dit om vir 'n rukkie huis toe te gaan, het Coenus voorgestel, om dan met 'n vars leër verdere oorwinnings te behaal. Curtius het in sy weergawe van Coenus se toespraak ook die troepe se bereidwilligheid om redelike take uit te voer, beklemtoon, maar dit duidelik gestel dat hulle voel dat die beoogde inval van 'n onbekende Indië te veel gevra is van 'n afgematte leër met verroeste wapens en stukkende klere. Hulle word reeds gedwing om weens klere-tekorte Persiese kleredrag te dra, en verval in vreemde en ontaarde kulture. Hierdie beoogde kampanje is volgens Coenus wel in pas met Alexander se groot gees, maar het nou te verhewe vir sy soldate geword (9.3.9).

Ontsteld het Alexander na sy tent gegaan. Die volgende dag is dieselfde offisierekorps ingelig dat hy van plan was om met sy opmars voort te gaan. Al weier alle Masedoniërs om te volg, weet hy dat die res van sy leër sal volg. Die Masedoniërs sou dan vry wees om huis toe te gaan, in die wete dat hulle hul koning in die steek gelaat het. Hierna het hy homself vir drie dae in sy tent onttrek, maar toe geen alternatiewe reaksie van sy soldate volg nie, het Alexander die senior offisiere van sy Metgeselle en sy persoonlike vriende (dus slegs Masedoniërs) ingeroep. Hy het hulle ingelig dat 'n spesiale offerande getoon het dat die tekens ongunstig was vir die oorsteek van die Hyphasis/Beas-rivier, en dat hy besluit het om nie verder te gaan nie. Alexander het besef dat hy verlore sou wees sonder sy Masedoniërs (Hammond 1981:214). 
Sy besluit is deur die leër met toejuiging begroet (Arrianus 5.28). Huldebetuigings voor die koninklike tent het gevolg, waarna dankoffers gebring en twaalf reuse-altare gebou is wat eeue later nog landmerke sou wees (Hammond 1981:215). $\mathrm{Na}$ verdere feesvierings het Alexander na die Hydaspes/Djelum teruggekeer en voorbereidings getref vir sy volgende veroweringsveldtog langs die Indus af tot by die see. Die soldate het hul volle steun aan hierdie opmars na die Suide gegee. Tarn (1948:2.102) glo egter dat die besondere bloeddorstige wyse waarop Suid-Indië hierna onderwerp is, mag dui op 'n leër wat uit frustrasie en tamheid seker wou maak dat geen weerstand vir môre sou oorbly nie. In sy veldtog teen die Malli, is Alexander ernstig gewond toe hy homself aan die voorpunt van 'n aanval teen die stadsmure bevind het. Alhoewel hierdie episode op laksheid van 'n teësinnige leër mag gedui het, is daar geen bewyse hiervoor nie (Hammond 1981:221-227).

Curtius (4.15-23) beweer dat die leër in die land van die Malli, waar baie hard geveg is, weer opstandig geraak het omdat hulle gedwing is om te veg in die landstreek oorkant die Ganges. Curtius was, as navolger van die Peripatetiese Skool in Athene, Alexander nie besonder goedgesind nie as gevolg van die breuk tussen $1 \mathrm{~g}$. en Aristoteles, en hierdie mededeling moet dus omsigtig beoordeel word (Tarn 1948:2.129). Sy stelling dat die leër op daardie stadium reeds die Ganges oorgesteek het, is in ieder geval foutief: Alexander was langs die Indus, ver wes van die Ganges.

In September 325 v.C. het Alexander die mond van die Indus bereik en sy terugmars na Mesopotamië begin, om nooit weer terug te keer na die oosgrens van sy nuwe Ryk nie.

\section{Bespreking}

In welke mate was oorlogstres, soos ons dit vandag ken, dan verantwoordelik vir Alexander se konfrontasie met sy leër? Oorlogstres word tans gedefinieer as die tydelike disintegrasie van 'n soldaat se psigologiese integriteit as gevolg van erge krygspanning (Strange 1969:75-93). Die simptoomkompleks is wyd uiteenlopend, soos hierbo vermeld, maar met gepaste terapie kan die oorgrote meerderheid pasiënte met verloop van tyd gerehabiliteer word. Die Amerikaanse ervaring in Viëtnam was dat die stressindroom kenmerkend vroeg ná oorlogblootstelling plaasgevind het. Dit het meer dikwels voorgekom by ouer soldate en persone met 'n onstabiele persoonlikheid. Faktore soos sterk kameraderie, vertroue in leiers, geloof in die saak waarvoor geveg word en goeie gesondheid, kan die individu teen oorlogstres beskerm (Elder \& Clipp 1988:131-154).

Die sindroom tas dan tipies 'n individuele soldaat aan, en nie 'n leër (of leërgroep) nie. Alexander se konfrontasie met sy leër by die Hyphasis/Beas-rivier val dan eintlik buite huidige oorlogstres-begrippe. Enige leër bestaan egter wel uit individue. Alexander se probleem van 326 v.C. kan dan uit hierdie gesigspunt benader word deur te let op die inhoud van Coenus se toespraak (wat die soldate se optrede aan die koning gemotiveer het), en ook deur op grond van ander beskikbare inligting afleidings te waag oor hoe die soldate deur die baie spesiale omstandighede van die tyd beïnvloed kon gewees het. Was 'n sleutelkomponent van die leër dalk deur oorlogstres verlam? 
Omdat Arrianus algemeen aanvaar word as die betroubaarste antieke bron vir die geskiedenis van Alexander (Retief \& Cilliers 1999:63-76), word sy weergawe van Coenus se toespraak oorweeg. Die Curtius-weergawe verskil ook nie beduidend hiervan nie. Alhoewel Arrianus se geskiedenis gebaseer was op kontemporêre inligting van Ptolemaeus en die sogenaamde Koninklike Joernale (bronne wat deur meeste geleerdes as geloofwaardig beskou word), is dit eers drie eeue na Alexander se dood geskryf. Arrianus se weergawe van Coenus se toespraak val dus in dieselfde kategorie as byvoorbeeld Pericles se Lykrede soos weergegee deur Thucydides. In geeneen van die gevalle waar toesprake in antieke geskiedskrywers se werke voorkom, is daar voorgegee dat dit die eksakte woorde van die spreker was nie. Inteendeel, dit was 'n geleentheid vir die skrywer om sy retoriese vaardigheid te toon, en vir tydgenote wat geskiedskrywing as 'n vorm van kuns beskou het, was dit as sodanig aanvaarbaar. Thucydides se "beleidsverklaring" hieroor toon egter dat daar gepoog is om so na as moontlik aan die feitelike waarheid te bly: "Ek het die toesprake só weergegee soos wat dit vir my gelyk het die paslikste was vir die onderskeie persone om by elke geleentheid te sê, terwyl ek so naby as moontlik bly aan die algemene strekking van wat werklik gesê is" (1.22).

Uit Coenus se voorspraak soos deur Arrianus weergegee (5.27.2-9), blyk dit dat die uitgedunde Masedoniërs (want dit is namens hulle wat hy sy pleitrede lewer) na soveel jare op die oorlogspad, nou fisies, maar veral geestelik moeg was, en dat hul verlang het na hulle tuisland en hul mense. Hy stel voor dat Alexander later sou kon terugkeer vir verdere oorwinnings, met 'n nuwe leër wat die afgryse van die huidige stryd nie ken nie. Dit is klaarblyklik die pleidooi van 'n lojale soldaat wat fisies maar ook geestelik die einde van die pad bereik het, en vir wie die afgryse van die oorlog nou oorweldigend raak. Hammond (1981:213-215) wys interessantheidshalwe daarop dat hierdie geen soldate-rebellie in die normale sin van die woord was nie - dat slegs die Masedoniërs betrokke was met 'n versoek dat Alexander nie verder ooswaarts trek nie, maar sonder om te eis dat hy dadelik terugkeer huis toe (alhoewel dit gesuggereer is). Coenus se toespraak is ook gelewer nadat hy eerbiedig sy helm afgehaal het, en alhoewel die koning drie dae geneem het om te antwoord, was daar intussen geen oproerigheid onder die soldate nie. Toe Alexander aandui dat hy sy ooswaartse opmars staak maar voortgaan met die moeilike verowering van Suid-Indië, het die Masedoniërs hierby ingeval.

Die Masedoniese leër was 'n professionele instelling van beroepsoldate direk verantwoordelik, en intiem verbonde, aan die koning (Hammond 1981:24). Daar kan geargumenteer word dat so 'n leërkorps nie geykte oorlogstres sal opdoen tensy strawwe nuwe stresfaktore na vore getree het nie. Dit moet ook onthou word dat alhoewel die Masedoniese komponent van Alexander se leër by die Hyphasis uitgedun was (een-sesde van die totaal), die totale soldatemag baie sterk was - dat Alexander by die aanvang van sy Indiese veldtog selfs soveel as 120000 soldate tot sy beskikking kon gehad het, die meerderheid huursoldate en Indiese en Iranese konskripsie-troepe (Hammond 1981:203). 'n Saak kan egter wel uitgemaak word vir buitengewone stresfaktore in die somer van 326 v.C.: 
(i) Kort tevore het die Masedoniërs by die Hydaspes-slag die baie traumatiese ondervinding gehad om vir die eerste keer teen 'n leër met 'n sterk element van oorlogsolifante te veg. Die ongevallesyfer was hoog en Alexander se leër was gedemoraliseer (Curtius 8.14, Arrianus 5.15-18, Wood 1997:190).

(ii) Volgens alle inligting was die somer-kampanje vanaf die Hydaspes/Djelum deur verskeie groot takriviere in die bolope van die Indus 'n nuwe en uitmergelende ondervinding. Die onbekende monsoen-seisoen was uitputtend en geharde weerstand het gesorg vir deurlopend strawwe oorlogvoering tot aan die oewers van die Hyphasis/Beas (Wood 1997:190-197; Tarn 1948:1.9798).

(iii) Arrianus (5.25.1-5) en Curtius (9.2.3) beweer dat Alexander en sy leër bewus geword het van groot riviere en magtige volke (met oorweldigende leërs, strydwaens en 'n oormag oorlogsolifante) in dié deel van Indië wat nou binnegeval sou word. Alhoewel Tarn (1948:2.280) meen dat daar geen bewys is dat Alexander en sy Masedoniërs van hierdie bedreiginge geweet het nie, is dit onwaarskynlik dat inwoners van die streek en Indiese soldate in sy leër nie daarvan geweet het en hulle ingelig het nie. Selfs sonder betroubare inligting, sou sulke gerugte die uitgeputte Masedoniërs sekerlik erg gekwel het. Dit is duidelik dat kennis van die Indiese vasteland baie gebrekkig was, en dat Alexander gemeen het dat 'n relatiewe kort veldtog hom by die "Oos-oseaan" en die einde van die bekende wêreld sou bring (Tarn 1948:2.286-296).

Dit is reeds genoem dat volgens die moderne siening die oorlogstressindroom 'n aantasting van individuele soldate is, en nie van leërs nie. Dit is ook onwaarskynlik dat sleutelaanvoerders onder die Masedoniërs wel aangetas was en so die krisis veroorsaak het. Volgens oorlewering was die protes georden, en het Coenus byvoorbeeld geen tekens van psigologiese disintegrasie getoon nie. Die impasse het ook snel verdwyn toe Alexander sy beoogde Indiese veldtog kanseleer. Tipiese oorlogstres het vandag wel 'n goeie prognose, maar genesing geskied nie so snel nie.

\section{Samevatting}

Volgens die diagnostiese DSM-III kriteria kan oorlogstres, soos vandag gedefinieer, nie blameer word vir Alexander se leëropstand van 326 v.C. nie. Die Masedoniese aksie is nie gekenmerk deur sielkundige versteurings by spesifieke individue nie, maar wel deur algemene beswaar teen hul koning se planne om Indië binne te val. Besondere stresfaktore was wel op die gegewe stadium ter sprake, maar dis te betwyfel of dit erg genoeg was om die oorlogstres-sindroom by 'n professionele leër, reeds lank in die stryd, uit te lok. Die tipiese simptoomkompleks is in Viëtnam byvoorbeeld opgemerk by soldate wat redelik kort tevore vanuit die burgerlike lewe na erge gevegstrauma oorgeplaas is (Tischler 1969:19-25).

Alexander se Masedoniërs is by die Hyphasis/Beas-rivier egter wel deur erge oorlogspanning tot hul protesoptrede beweeg - iets wat nooit tevore gebeur het nie, maar wel twee jaar later by Opis herhaal sou word (Tarn 1948:2.286-296). In Coenus se pleidooi verwys hy na sy makkers se uitputting (fisies, maar veral psigies) en hulle verlange om ná sewe jaar van intense oorlogvoering weer terug te keer na hul 
vaderland en families. Alhoewel hierdie nie volgens DSM-III kriteria as die tipiese oorlogstres-sindroom kwalifiseer nie, is dit tog interessant om daarop te let dat toe oorlogstres en psigiese disintegrasie vir die eerste keer wetenskaplik as entiteit erken is - tydens die Amerikaanse Burgeroorlog - dit toegeskryf is aan "nostalgie", bedruktheid veroorsaak deur lang afwesigheid van huis en haard (Bourne 1969:219). Ons wil dus die hipotese voorstel dat die unieke reaksie van Alexander se gesoute Masedoniërs op die grens van Indië in die somer van 326 v.C., wel as 'n geldige variant van oorlogstres gesien kan word. Volgens Arrianus (5.27) was 'n hoofbeweegrede vir die Masedoniërs se protes dan ook hul intense verlange om weer hul vaderland te sien.

\section{BIBLIOGRAFIE}

Allerton, W S 1969. Army psychiatry in Viëtnam. In Bourne 1969:10-14.

Bourne, P G 1969. Military psychiatry and the Viëtnam war in perspective. In Bourne 1969:219-236.

Bourne, P G 1969. The psychology and physiology of stress. New York/London: Academic Press.

Brunt, P A (trans.) 1949. Arrian. History of Alexander. 2 Vols. Loeb Classical Library. Cambridge: Harvard University Press.

Elder, G H \& Clipp, E C 1988. Combat experience, comradeship and psychological health. In Wilson et al. 1988:131-154.

Glass, A J 1969. Introduction. In Bourne 1969:xiv-xxx.

Hammond, N G L 1981. Alexander the Great. London: Chatto \& Windus.

Louw, D A 1989. Suid-Afrikaanse handboek van abnormale gedrag. Johannesburg: Southern Boekuitgewers.

Marmar, C R \& Horowitz, M J 1988. Diagnosis and phase-oriented treatment of posttraumatic stress disorders. In Wilson et al.1988:81-103.

Retief, F P \& Cilliers, L 1999. The death of Alexander the Great. Acta Academica 31.1:63-76.

Rolfe, C (trans.) 1946. Curtius. History of Alexander. 2 Vols. Loeb Classical Library. Cambridge: Harvard University Press.

Smith, C F (trans.) 1956. Thucydides. History of the Peloponnesian War. Vol. 1. Loeb Classical Library. Cambridge: Harvard University Press.

Strange, R E 1969. Effects of combat stress on hospital ship psychiatric evacuees. In Bourne 1969:75-93.

Tarn, W W 1948 (1979). Alexander the Great. 2 Vols. Cambridge: Cambridge University Press.

Tischler, G L 1969. Patterns of psychiatric attrition and behaviour in a combat zone. In Bourne 1969:19-45.

Wilson, J P, Hazel, Z \& Kahana, B 1988. Human adaptation to extreme stress. New York/London: Plenum Press.

Wood, M 1997. In the footsteps of Alexander the Great. London: BBC Books. 